\title{
Application of electrokinetic in controlling heavy metals migration in sand: A feasibility study
}

\author{
Cindy Liew, and Leonard L. P. Lim* \\ Faculty of Engineering, Universiti Malaysia Sarawak, 94300 Kota Samarahan, Sarawak, Malaysia. \\ *Corresponding author: llpleonard@feng.unimas.my \\ Date Received: $26^{\text {th }}$ August 204 \\ Date Published: $1^{\text {st }}$ October 2014
}

\begin{abstract}
Uncontrolled migration of heavy metals from human activities in the subsurface can lead to the degradation of environmental quality and potential use of soil and groundwater. This paper studies the feasibility of using electrokinetics in controlling the migration of heavy metals in sand. Copper and iron (initial concentration of $100 \mathrm{mgL}^{-1}$ ) are the target heavy metals in this study as they are the most commonly found heavy metals from human activities such as mining and land filling. The performance of electrokinetic in controlling the migration of these heavy metals is tested in a sand tank at combination of water velocity and electrical gradient of $1.3 \mathrm{~cm} \mathrm{~h}$ $1,0.5 \mathrm{~V} \mathrm{~cm}^{-1}$ and $0.88 \mathrm{~cm} \mathrm{~h}^{-1}, 1 \mathrm{~V} \mathrm{~cm}^{-1}$, respectively. The formation of gas at electrodes, scouring on carbon anode and corrosion of crocodile clips during experiment $\left(0.88 \mathrm{~cm} \mathrm{~h}^{-1}, 1 \mathrm{~V} \mathrm{~cm}^{-1}\right)$ showed the occurrence of electrokinetics. Further studies need to be conducted to optimize the operating conditions for effective application of electrokinetic in controlling heavy metals migration in sand.
\end{abstract}

Keywords: Electrokinetic, heavy metals, sand tank experiment, carbon electrode

\section{INTRODUCTION}

$\mathrm{M}$ IGRATION of heavy metals in ground can cause problem such as pollution of groundwater resources and contamination of soil. The presence of heavy metal in groundwater can affect the quality of water resources such as drinking and irrigation water. Improper disposal of mine waste at an open pit copper mine led to the leaching of copper discharge into groundwater resources at the Mamut Basin, Sabah making the groundwater unsuitable for daily consumption [1]. Various techniques for controlling the migration of heavy metals in groundwater have been developed, such as in-situ bioremediation and phytoremediation, which incur low cost and maintenance as it depends on the natural up take of heavy metals in soil and groundwater [2,3]. Nevertheless, these techniques typically have slow reaction rate, susceptible to ground conditions, may produce toxic by-products in oxygen deficient conditions and only applicable for shallow depths within the reach of the roots [4]. Thus, there is a need for more effective and rapid technique to control the contamination of heavy metals in groundwater such as electrokinetic.

Electrokinetic is a technology which utilizes electric (direct) current to control the migration of contaminated compound in ground such as radionuclide, heavy metals, certain organic compounds and mixed inorganic species [5]. It is effective in controlling the migration of heavy metals in soil by applying direct current though the electrodes installed in ground. The electrical gradient facilitates the electromigration of the ionic species, cations (heavy metals such as copper and iron) to cathode and anions (such as sulphate and nitrate) to anode [6,7]. Various electrokinetic configurations had been developed such as (i) using cation-selective membrane placed in front of cathode, (ii) using porous surfactant-coated ceramic anode casings, (iii) Lasagna ${ }^{\mathrm{TM}}$ process, (iv) Electro-Klean ${ }^{\mathrm{TM}}$ process, (v) electrokinetic bioremediation, (vi) electrochemical geooxidation, (vii) electrochemical ion exchange, and (viii) Electrosorb ${ }^{\mathrm{TM}}$ [7]. Its advantages over other techniques are (i) faster groundwater remediation than bioremediation [4], (ii) controllable application throughout the process [5], (iii) simple in-situ installation without much excavation required, and (iv) can be applied in both saturated and partially saturated soil conditions, thus not directly affected by groundwater level fluctuation [7]. There are four main mechanisms in electrokinetic which are electrolysis, electrophoresis, electroosmosis, and electromigration which will be discussed in the following section.

Despite the advantages, the performance of electrokinetic can be affected by the initial concentration of contaminant, mobility of contaminant, hydrogeology characteristics, and current and voltage applied [8]. Most previous research focused on the application of electrokinetics on saturated fine-grained soils, while limited studies were conducted on soil with greater hydraulic conductivity such as sandy soil. Mattson and Lindgren [9] showed that electrokinetics can be applied for unsaturated sandy soil through laboratory experiments. The study investigated the effect of the initial and final concentration

This work was funded by Ministry of Education through Research Acculturation Grant Scheme (RAGS/c(6)/939/2012(40)).

Cindy Liew is with the Department of Civil Engineering, Faculty of Engineering, Universiti Malaysia Sarawak, 94300 Kota Samarahan, Sarawak, Malaysia (e-mail: cindyliewcindyliew@gmail.com).

Leonard L. P. Lim is with the Department of Civil Engineering, Faculty of Engineering, Universiti Malaysia Sarawak, 94300 Kota Samarahan, Sarawak, Malaysia (corresponding author phone: +608-258-3308; fax: +608-258-3410; e-mail: 1lpleonard@ feng.unimas.my). 
of heavy metals (copper and iron) in sand where electrokinetic manages to extract chromate from unsaturated soil. The carbon electrodes are used to avoid the introduction of new species during the process through electrode oxidation and reduction. Direct current (DC) power supply is used to apply the direct current within the soil medium through the electrode. This experiment based study represents a small scale in-situ treatment of contaminated groundwater.

\section{ELECTROKINETICS}

\subsection{Electrokinetics mechanism}

Electrokinetic mechanism can be explained in the following four stages which are electrolysis, electrophoresis, electroosmosis, and electromigration. The electrokinetic process is initiated by applying direct current into saturated or partially saturated soil, through the positive (anode) and negative (cathode) terminal.

\section{Stage 1: Electrolysis at the electrodes}

Applying direct current to soil promotes the electron transfer of ionic species towards the electrodes of opposite charge, through the electrolysis of water. Oxidation occurs at anode where oxygen gas and hydrogen ion are released (1). The generation of hydrogen ion decreases the $\mathrm{pH}$, forming an acidic medium around the anode. Reduction occurs at cathode where hydrogen gas and hydroxide ion are released (2). In contrast, the cathode generates hydroxides ions, forming an alkaline medium $[10,11,12]$. The electrolysis of water is as shown in (1) and (2).

Oxidation at the anode: $\quad 2 \mathrm{H}_{2} \mathrm{O} \rightarrow \mathrm{O}_{2}+4 \mathrm{H}^{+}+4 \mathrm{e}^{-}$

Reduction at the cathode: $2 \mathrm{H}_{2} \mathrm{O}+2 \mathrm{e}^{-} \rightarrow \mathrm{H}_{2}+2 \mathrm{OH}^{-}$

\section{Stage 2: Electroosmosis of water}

Electroosmosis refers to the movement of water molecule in the electric field condition. In soil medium, normally soil particles are negatively charged and results in electroosmotic flow towards the cathode. The hydrogen $\left(\mathrm{H}^{+}\right)$and hydroxide $\left(\mathrm{OH}^{-}\right)$ions generated at anode and cathode, respectively, will move across the soil to the electrode of opposite charge [7,13]. The $\mathrm{H}^{+}$ions move from anode to concentrate at cathode, and vice versa for $\mathrm{OH}^{-}$ions. This phenomena lead to the reduction and increment of $\mathrm{pH}$ at cathode and anode, respectively. Simultaneously, air bubbles are produced at both electrodes: cathode (hydrogen gas, $\mathrm{H}_{2}$ ) and anode (oxygen gas, $\mathrm{O}_{2}$ ). The mobility of $\mathrm{H}^{+}$ions is 1.8 times faster than of $\mathrm{OH}^{-}$ions [6,12]. $\mathrm{H}^{+}$ions will concentrate promote the acidic environment toward the cathode, thus dissolve the heavy metals in ionic form across the soil medium.

\section{Stage 3: Electropherosis of charged particles}

Charged particles, dispersed particles and colloids which bound to mobile particulate matter attract to the opposite charge electrodes. As the water ions move during electrokinetic, the charged particle will follow the electroosmotic flow to reach to the opposite charged electrodes. Positively charged particle will attract to the negatively charged soil surface and hence displace the heavy metal that attach to the soil particles surface at alkaline condition. Thus, heavy metal ions will be in the soluble phase in soil medium.

\section{Stage 4: Electromigration of heavy metal ions}

Electromigration refers to the transport of ionic species in the moist environment towards the opposite charge electrodes when electric field is applied. Heavy metals ions are likely to be adsorbed onto the negatively charged soil particles surface. Acidic environment will hinder heavy metal contaminants from absorbed to the soil particle surface and dissolved them in ionic form in the subsurface. Hydrogen ions in acidic environment will displace the heavy metal ions from adsorbing to the soil particles surface [13], allows heavy metals ions migrate in groundwater and concentrated at cathode [6,14]. Further contaminants removal work may be done at cathode such as electroplating, pumping near the electrode, complexing with ion exchange resins, or electrodeposition near cathode [7]. Figure 1 shows the migration of ionic species across the soil within electric field and electrolysis of water at electrodes [5]. 


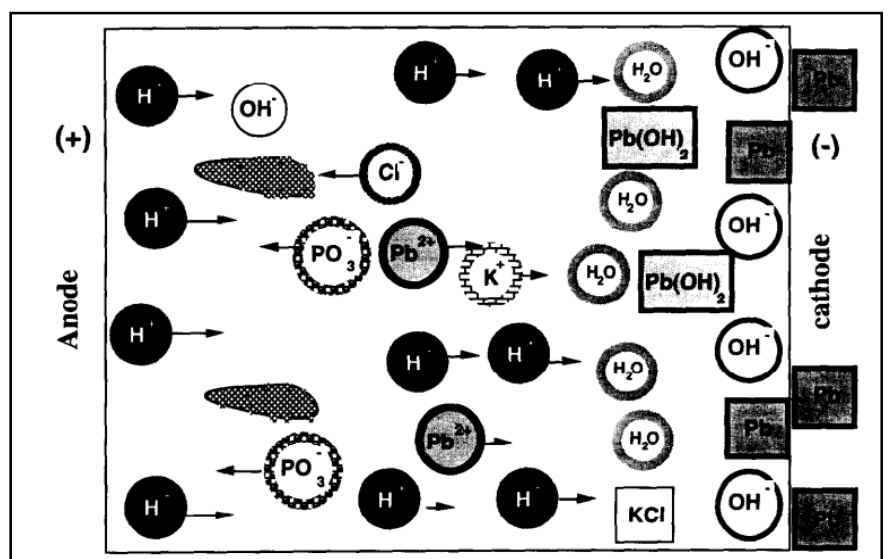

Figure 1 Migration of ionic species across the soil within electric field and electrolysis of water at electrodes [5]

\subsection{Factors affecting the performance of electrokinetic}

The efficiency of electrokinetic in controlling the heavy metal migration is primarily governed by the current. There are several factors which can lead to the reduction of current density such as polarization at electrodes, premature precipitation, and sorption of contaminant onto soil particles surface. These factors were explained as follow.

(i) Polarization at electrodes

Activation, resistance and concentration polarization at the electrodes can cause the reduction of electrical conductivity [7]. Activation polarization refers to the situation where the gas bubbles cover the electrodes, oxygen gas at anode and hydrogen gas at cathode. These gas bubbles act as good insulators for reducing the electric conductivity and thus reduce the current density during the process of electrokinetic. Resistance polarization occurs when the metal and impurities react with the hydroxide ions, forming metal hydroxide precipitates at cathode. Metal hydroxides, insoluble salt and other impurities could precipitate on the cathode surface which hinders the electric conductivity. Concentration polarization refers to the attraction of $\mathrm{H}^{+}$and $\mathrm{OH}^{-}$which generated at anode and cathode, respectively, towards to the opposite charge electrodes. If the acidic and alkaline conditions when the $\mathrm{H}^{+}$and $\mathrm{OH}^{-}$generated are not been neutralize, the current will drop.

(ii) Premature precipitation

Heavy metal ions may react with $\mathrm{OH}^{-}$ions in the soil medium near to cathode and precipitate in metal hydroxides, which this phenomena known as premature precipitation. The premature precipitant will fill the voids in soil thus reducing the hydraulic conductivity of soil and gradually reduce the current density $[14,15]$. Enhancements techniques may be applied to obtain the desired performance of electrokinetic such as add acetic acid or surfactants to the soil medium.

(iii) Sorption of contaminant onto soil particles surface

Heavy metals are mostly to be attracting onto the negatively charged soil particles in natural environment which involve adsorption or ion exchange [7,13]. Acidic environment must be introduced in the elecrokinetic to allow heavy metals to desorb from soil particles surface into soluble phase and migrate in the groundwater. Hydrogen ions will then displace the heavy metal ions from adsorbing to the soil particle in acidic condition [14]. Higher carbonates and organic matter in soil medium will react with the positively charge heavy metal contaminants and thus lower the heavy metals migration and electrokinetic performance.

\section{MATERIAL AND METHODS}

\subsection{Experimental sand tank}

The sand tank (Figure 2 a-c) was used to simulate the performance of electrokinetic in controlling migration of heavy metal in sand. It had an internal dimension of $400(\mathrm{~W}) \times 1100(\mathrm{~L}) \times 150 \mathrm{~mm}(\mathrm{H})$. It had two channels and each channel is $200 \mathrm{~mm}$ wide. The lengths of the inlet, soil and outlet chamber were 50, 1000 and $50 \mathrm{~mm}$ respectively. The chambers of each channel were separated by $5 \mathrm{~mm}$ thick perforated plates lined with $60 \mu \mathrm{m}$ mesh. A Longer BT100-2J peristaltic pump was used to control the flow of heavy metal solution through the inlet chamber to provide uniform flow and heavy metal concentration across the cross section area of the soil medium. The soil chamber was filled with sand, particle size ranged between 150 and $300 \mu \mathrm{m}$. Sand was used due to its higher permeability and gives faster transportation rate than clay and silt. The soil chamber consists of 21 sampling points $(50 \mathrm{~mm}$ from bottom of the tank) and 6 electrodes ( 3 anode and 3 cathode electrodes) for each channel (Figure 2). Each sampling point consists of a sampling tube made of perforated PE tubing (3 $\mathrm{mm}$ holes) lined with $60 \mu \mathrm{m}$ stainless steel mesh to retain sand as the solution flow through. Samples were taken from the sampling tube using a $10 \mathrm{~mL}$ plastic syringe with modified tube extension to enable sampling at $50 \mathrm{~mm}$ depth. The experiments were conducted for 9 and $60 \mathrm{~h}$. 

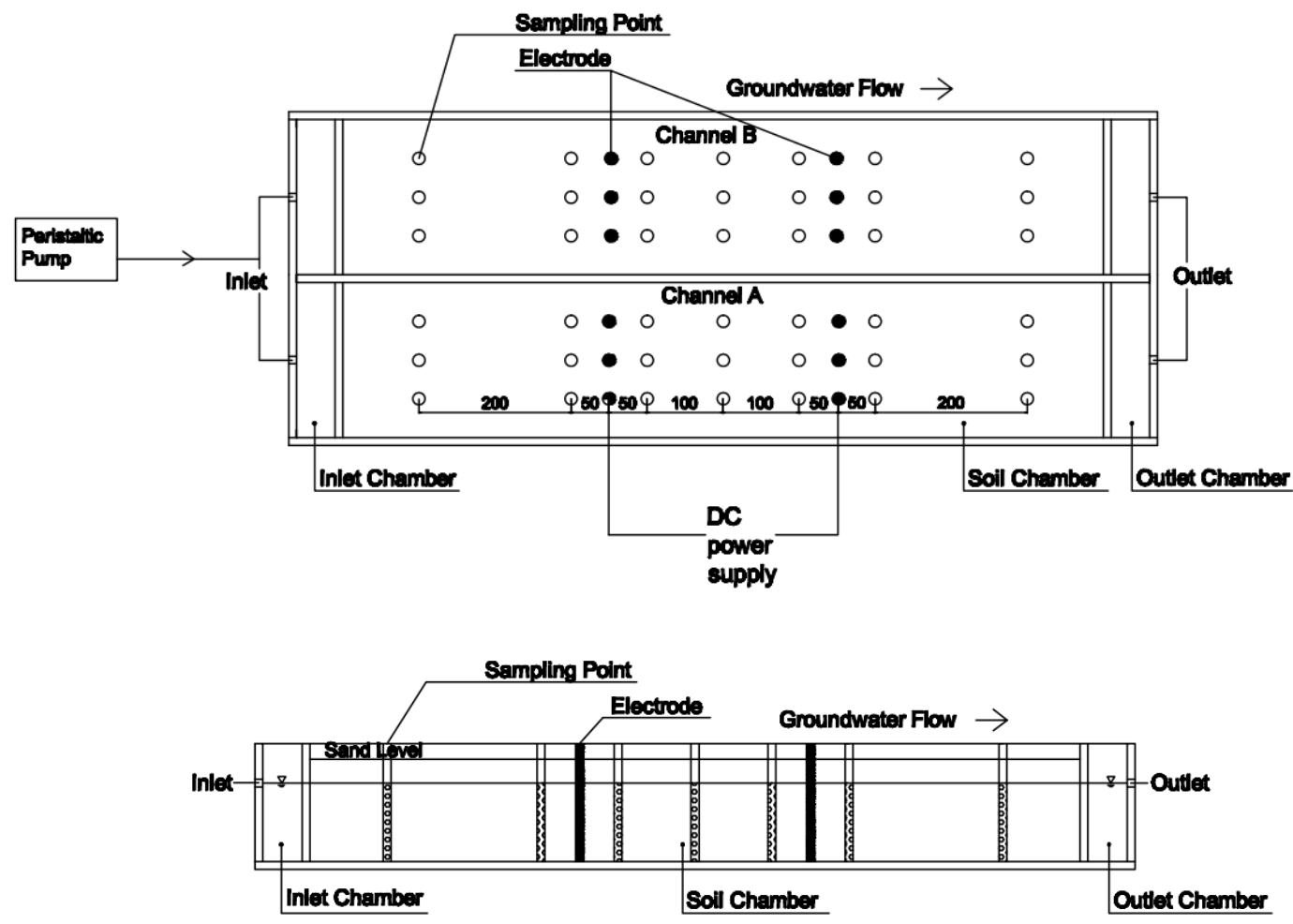

(b)

(c)

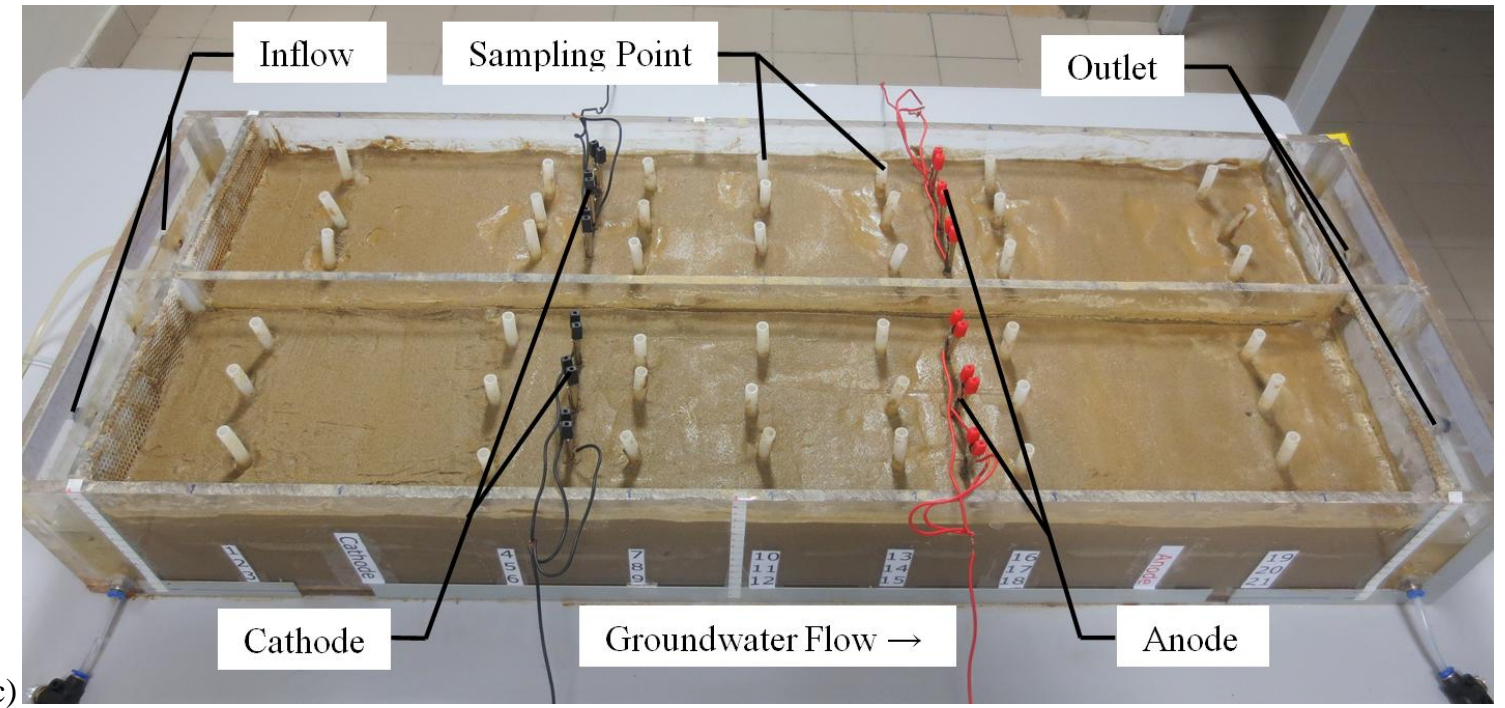

Figure 2 Experimental setup of the sand tank (a) plan view, (b) side view and (c) photo of sand tank showing the sampling points and electrodes. (All units in millimeter.)

\subsection{Direct current}

Electrokinetics is typically operated on constant voltage (direct current), with potential gradients ranging from 0.2 to $2 \mathrm{~V}$ $\mathrm{cm}^{-1}$, generating small current through soil [16]. Yeung [8] reported the typical electrical gradient applied in most laboratory electrokinetic experiments and on site is $1 \mathrm{~V} \mathrm{~cm}^{-1}$. In this study, the voltage was maintained at $30 \mathrm{~V}$, with distance between anode and cathode of 600 and $300 \mathrm{~mm}$, for first and second trial run, respectively (Figure 2), corresponding to an electrical gradient of 0.5 and $1 \mathrm{~V} \mathrm{~cm}^{-1}$. The current or voltage for the treatment is controlled using an Extech 382270 DC power supply.

\subsection{Synthetic Groundwater}

Synthetic contaminated groundwater was used in the experiment to eliminate potential interference of natural occurring groundwater constituent. $100 \mathrm{mgL}^{-1}$ copper solution was prepared by adding copper sulphate into distilled water. $100 \mathrm{mgL}^{-1}$ iron solution was prepared by adding iron (III) nitrate nonahydrate into distilled water. 


\section{UNIMAS e-Journal of Civil Engineering}

\section{RESULTS AND DISCUSSION}

The results from experimental sand tank were presented as for the water velocity and electrical gradient of $1.3 \mathrm{~cm} \mathrm{~h}^{-1}$ and $0.5 \mathrm{~V} \mathrm{~cm}^{-1}$, followed by $0.88 \mathrm{~cm} \mathrm{~h}^{-1}$ and $1 \mathrm{~V} \mathrm{~cm}^{-1}$. The duration of the experiments were $9 \mathrm{~h}$ and $60 \mathrm{~h}$, respectively. The electrokintics functioned in sand at a low water velocity of $0.88 \mathrm{~cm} \mathrm{~h}^{-1}$ and electrical gradient of $1 \mathrm{~V} \mathrm{~cm}^{-1}$.

\subsection{Effect of water velocity on electrokinetic}

The water applied in the sand tank experiments were 1.3 and $0.88 \mathrm{~cm} \mathrm{~h}^{-1}$. The electrokinetic did not work well at water velocity of $1.3 \mathrm{~cm} \mathrm{~h}^{-1}$ as the advection of water was too fast for electroosmosis and electromigration in sand, which has high hydraulic conductivity. Heavy metals at the downstream of the tank need to move against the groundwater flow to reach cathode. The attraction force between heavy metals and cathode and ions motion energy which contribute to its movement was faster than the groundwater flow energy to enable the effect of electrokinetics.

From observation, there was no deposition or precipitation of metal or metal hydroxide near the cathode for both experiments. There was gas bubbles generated at the electrodes which was produced by the electrolysis of water at electrodes. At water velocity of $0.88 \mathrm{~cm} \mathrm{~h}^{-1}$, there were some indications of electrokinetic process occurring during the experiment i.e. gas bubbles formation, black region around anode, scouring of carbon electrodes, and corrosion of crocodile clip.

\section{(i) Formation of gas bubbles}

Figure 3 (a-d) shows the formation of gas bubbles at the electrodes. This indicated that there was electrolysis at the electrode where oxygen and hydrogen gas released at anode and cathode, respectively for both Channel A and B. This was a continuously formation of gas bubbles through the whole experiment.

(a)

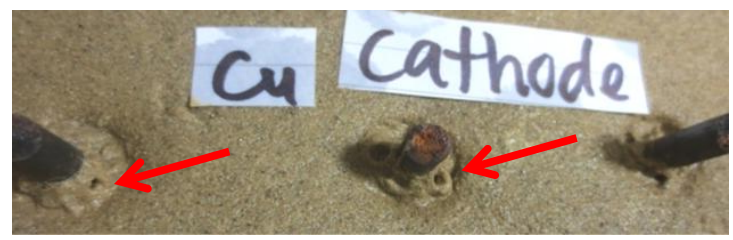

(c)

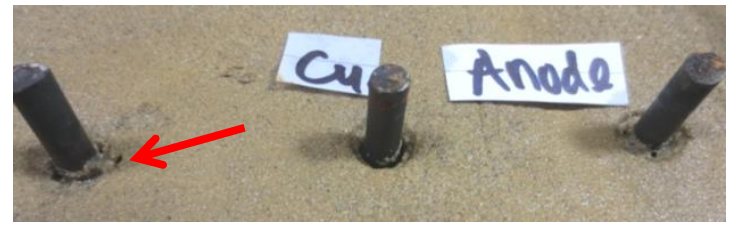

(b)

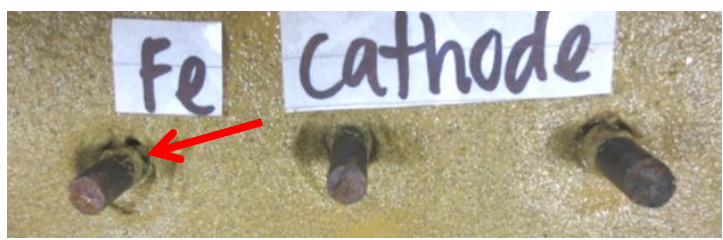

(d)

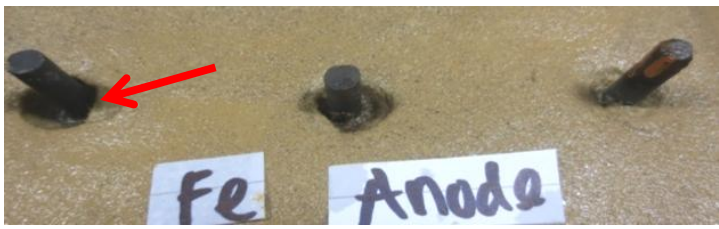

Figure 3 Formation of gas bubble near to the electrode, (a) and (c) represent the cathode and anode in soil contaminated with copper sulphate solution, while (b) and (d) represent the cathode and anode in soil contaminated with iron nitrate solution

\section{(ii) Formation of black region around carbon anode}

Figure 4 (a-c) shows the comparison of carbon anode and cathode after the experiment $\left(0.88 \mathrm{~cm} \mathrm{~h}^{-1}, 1 \mathrm{~V} \mathrm{~cm}^{-1}\right)$. The black region around carbon anode (Figure $4 a$ and $b$ ) indicated the carbon anode likely serves as sacrificial electrode during the operation. The region around cathode remains clean from any carbon residue (Figure 4c).

(a)

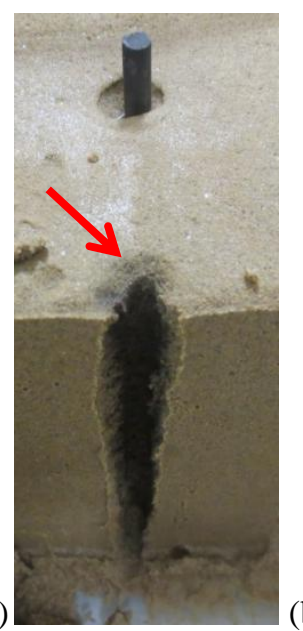

(b)

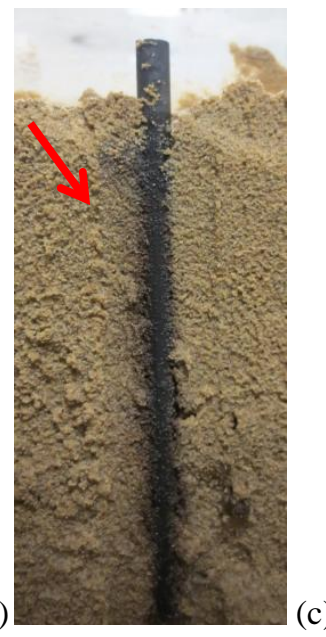

Figure 4 Comparison for anode and cathode after experiment: (a) Black region around anode formed after the experiment indicating carbon anode is likely sacrificial electrode, (b) view of the black region at Channel B before carbon anode was removed from sand, and (c) clear view of sand after carbon cathode is removed from its position 


\section{UNIMAS e-Journal of Civil Engineering}

(iii) Scouring of carbon electrode

Observation on carbon electrodes have been done after the experiment. Due to the sacrificing of electrode, the surface of carbon anode was scoured. Figure 5a shows the rough surface of carbon anode compared to the smooth surface of carbon cathode after the experiment (Figure 5b), implying that some of carbon anode reacted during the electrokinetic process.

(a)

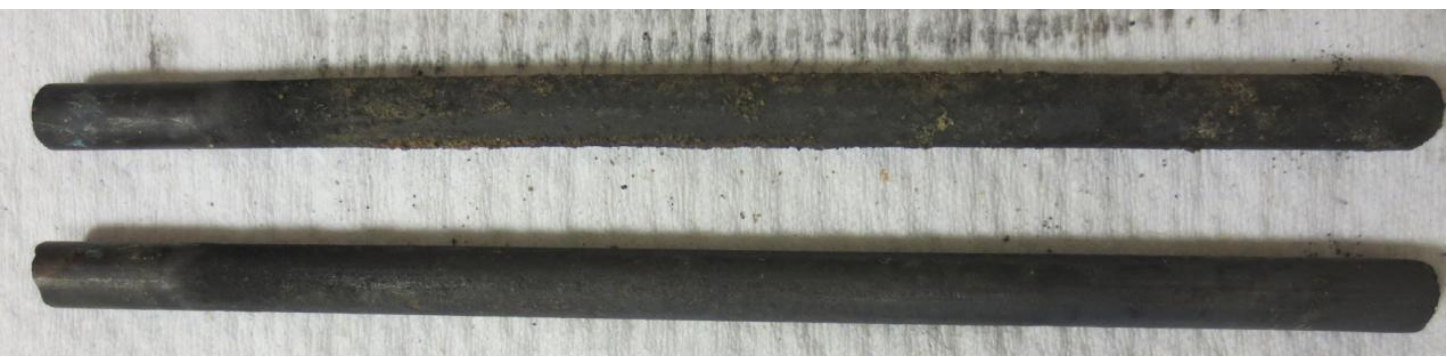

(b)

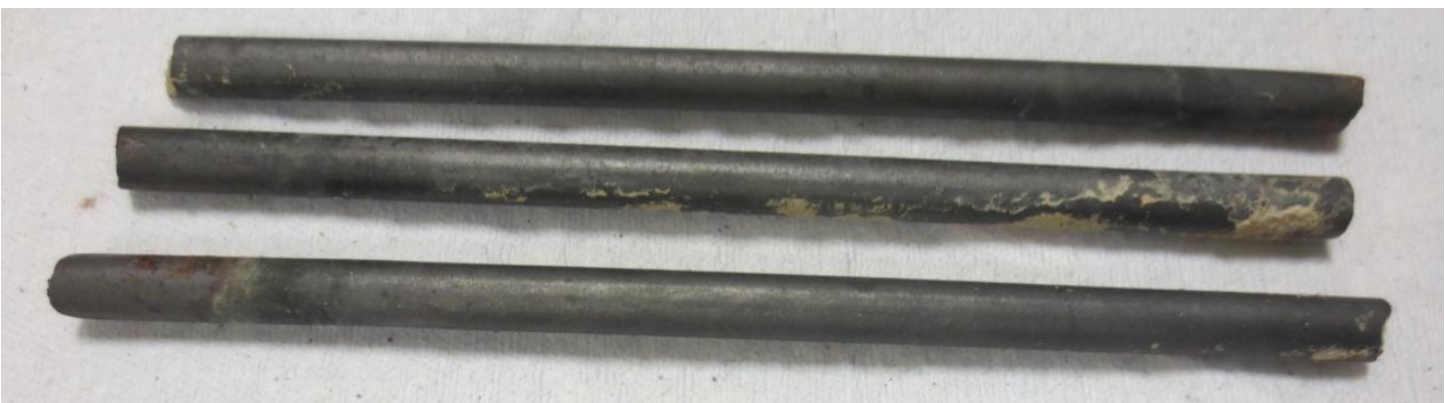

Figure 5 (a) The rough surface of carbon anode indicating carbon reacted during experiment and (b) smooth surface of carbon cathode after experiment

(iv) Corrosion of crocodile clip

The mild steel crocodile clip connected to the electrodes corroded rapidly due to metal oxidation during the experiment. Figure 6 shows rust (iron oxide) on the crocodile clip and the end of electrode.

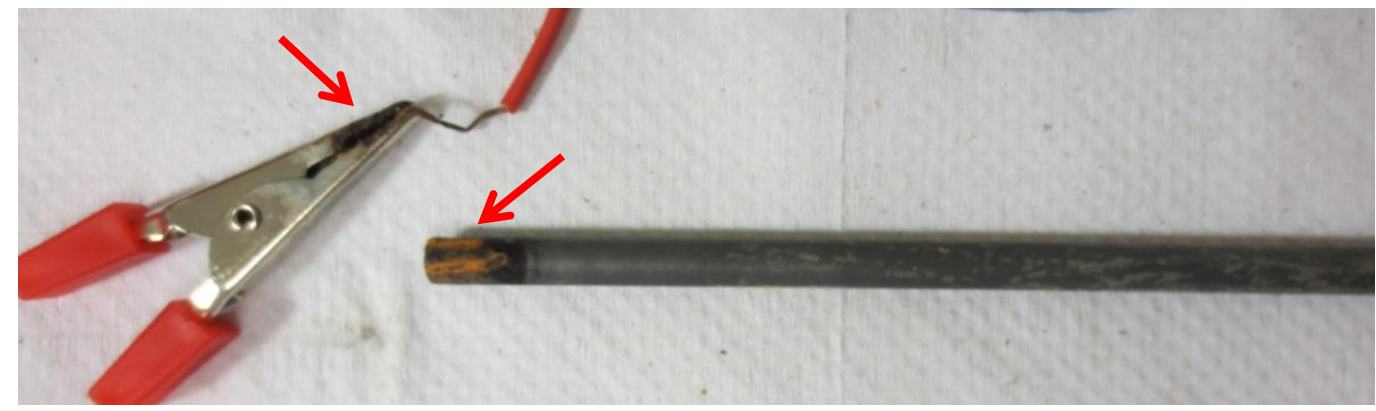

Figure 6 Corrosion of crocodile clip indicating oxidation of the mild steel clips

\subsection{Effect of electrical gradient on electrokinetic}

The DC power supply was fixed at $30 \mathrm{~V}$. The effect of electrical gradient was observed by placing the electrodes at 60 and $30 \mathrm{~cm}$, respectively. During the experiment at water velocity of $1.3 \mathrm{~cm} \mathrm{~h}^{-1}$, the electrodes were arranged $60 \mathrm{~cm}$ apart, corresponding to electrical gradient of $0.5 \mathrm{~V} \mathrm{~cm}^{-1}$. Besides the fast water advection, the electrokinetics did not function well due to the electrical gradient applied, which is half of the electrical gradient of at least $1 \mathrm{~V} \mathrm{~cm}^{-1}$ reported in the literature $[8,16]$. Page and Page [16] suggested the suitable electricalgradient for laboratory experiments is $2 \mathrm{~V} \mathrm{~cm}^{-1}$.

The electrokinetic during the experiment at water velocity of $0.88 \mathrm{~cm} \mathrm{~h}^{-1}$, showed some indication of electrokinitics reaction when the electrodes were placed $30 \mathrm{~cm}$ apart, corresponding to electrical gradient of $1 \mathrm{~V} \mathrm{~cm}^{-1}$. This effect of electrical gradient on electrokinetic is in line with Acar et al. [5] who observe an effective performance of $1 \mathrm{~V} \mathrm{~cm}^{-1}$ in electrokinetic.

\subsection{Migration of heavy metals}

In this study, there was no visible deposition or precipitation of metal or metal hydroxide around cathode. There was precipitate of iron oxide observed at the inlet of soil chamber (Figure 7) as water flow through the experimental tank. The orange region indicates that the precipitate of iron oxide was trapped among the voids in sand. 


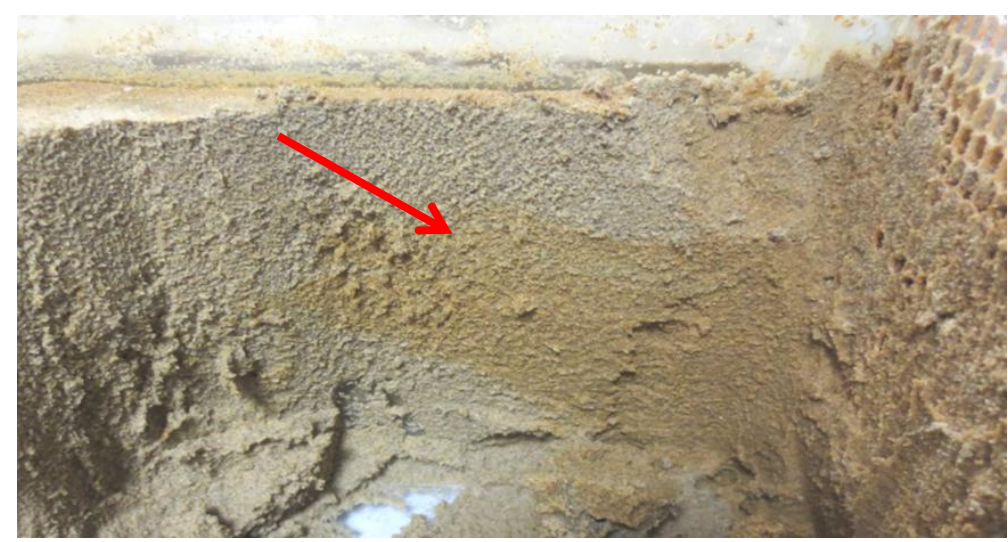

Figure 7 Orange region at the inlet of soil chamber indicating the immobilization of some iron oxides

The heavy metals were likely to be precipitate on the soil voids in natural environment [7]. It was found that the sand environment did not dissolve all the iron near to the inlet chamber where the heavy metals precipitate in their oxides between soil voids. Iron which dissolved in their soluble phase will migrate with the groundwater flow to the downstream of the tank. If the acidic environment is introduce at the inlet chamber towards the soil chamber, the hydrogen ions will then introduce acidic environment and dissolve all the precipitation of heavy metals. This observation of soil indicated that the sand environment in the experiment is not suitable to fully dissolve the iron ions.

\section{CONCLUSIONS}

This study showed that electrokinetic is applicable for controlling the migration of heavy metals in sand, subjected to water velocity and electrical gradient. The gas formation, scouring on carbon anode and corrosion of crocodile clips during experiment at $0.88 \mathrm{~cm} \mathrm{~h}^{-1}\left(1 \mathrm{~V} \mathrm{~cm}^{-1}\right)$ indicated the occurrence of electrokinetic process. Further work will involve experiments conducted over a longer period such as weeks in order to determine the suitable operating condition to obtain the desired electrokinetic performance.

\section{ACKNOWLEDGMENT}

The authors would like to thank the Ministry of Education for funding this research through Research Acculturation Grant Scheme (RAGS/c(6)/939/2012(40)) and Universiti Malaysia Sarawak for the facilities.

\section{REFERENCES}

[1] Ali, M.F., Heng, L.Y., Ratman, W., Nais, J. and Ripin, R., 2004. Metal Distribution and Contamination of the Mamut River, Malaysia, Caused by Copper Mine Discharge. Bulletin of Environmental Contamination and Toxicology, Vol 73, pp.535-542.

[2] Juwarkar, A.A., Singh, S.K., Mudhoo, A., 2010. A comprehensive overview of elements in bioremediation. Revolution of Environment Science Biotechnology, Vol 9, pp.215-288.

[3] Krishnani, K.K. and Ayyapan, S., 2006. Heavy Metal remediation of Water Using Plants and Lignocellulosic Agrowastes. Revolution of Environment Contamination Toxicology, Vol 188, pp.59-84.

[4] Cameselle, C., Chirakkara, R.A., Reddy, K.R., 2013 Electrokinetic-enhanced phytoremediation of soils: Status and opportunities. Chemosphere, Vol 93, pp. 626-636.

[5] Acar, Y.B., Gale, R.J., Alshawabkeh, A.N., Marks, R.E., Puppala, S., Bricka, M. and Parker R., 1995. Electrokinetic Remediation: Basic and Technology Status. Journal of Hazardous Materials, Vol 40, pp. 117-137.

[6] Ghosh, P.K., Balagurunathan, S., and Basha, C.A., 2012. Electrokinetic migration of nickel [Ni(II)] in contaminated sludge. Journal of Hazardous, Toxic, and Radioactive Waste, Vol 16, pp.201-206.

[7] Virkutyte, J., Sillanpää, M. and Latostenmaa, P., 2002. Electrokinetics soil remediation - critical review. The Science of the Total Environment, Vol 289, pp.97-121.

[8] Yeung, A.T., 2011. Milestone developments, myths, and future directions of electrokinetic remediation. Separation Purification Technology. doi: 10.1016/j.seppur.2011.01.022

[9] Mattson, E.D. and Lindgren, E.R., 1995. Electrokinetic extraction of chromate from unsaturated soils. American Chemical Society, 1995, pp.11-20.

[10] Athmer, C., Ruef, C., Jones, T.J. and Wilkens, R.J., 2013. Desalinazation of kaolin soil using radial electromigration and elecroosmosis. Journal of Harzardous, Toxic and Radioactive Waste, Vol 17, pp.16-20.

[11] Gu, Y.Y. and Yeung, A.T., 2012. Use of citric acid industrial wastewater to enhance electrochemical remediation of cadmium-contaminated natural clay. GeoCongres ASCE 2012, pp.3995-4004.

[12] Hodges, D.A., Fourie, D., and Thomas, D. R., 2013. Overcoming permanganate stalling during electromigration. Journal of environmental engineering, 2013, Vol 139, pp.677-684.

[13] Acar, Y.B. and Alshawabkeh, A.N., 1996. Electrokinetic remediation. I: Pilot-scale tests with lead-spiked Kaolinite. Journal of geotechnical engineering, Vol 122, pp.173-185.

[14] Xiao, M., Love, A.D. and Teng Z., 2009. pH variation and its effect on metal concentration during electrokinetics. World Environmental and Water Resources Cogress 2009, pp.2590-2592.

[15] Sah, J. and Lin, L.Y., 2000. Heavy metal removal using electrokinetic technology. Environmental and pipeline engineering, ASCE journal, pp.368377. 
UNIMAS e-Journal of Civil Engineering

[16] Page, M.M. and Page, C.L., 2002. Electroremediation of contaminated soils. Journal of Environmental Engineering. Vol. 28(3), pp.209-219. 